\title{
Local Concentrations of CC-Chemokine-Ligand 18 Correlate with Tumor Size in Non-small Cell Lung Cancer and Are Elevated in Lymph Node-positive Disease
}

\author{
SEVERIN SCHMID ${ }^{1}$, UYEN-THAO LE ${ }^{1}$, BENEDIKT HAAGER ${ }^{1}$, OLGA MAYER ${ }^{1}$, IRENE DIETRICH ${ }^{2}$, \\ MIRJAM ELZE $^{1}$, LARS JOHANN KEMNA ${ }^{2}$, GERNOT ZISSEL ${ }^{3}$ and BERNWARD PASSLICK ${ }^{1}$ \\ Departments of ${ }^{1}$ Thoracic Surgery, ${ }^{2}$ Radiology, and ${ }^{3}$ Pneumology, \\ University Medical Center Freiburg, Freiburg, Germany
}

\begin{abstract}
Background: The tumor microenvironment plays a critical role in tumor growth and spreading. Tumor-associated macrophages (TAM) make up a large proportion of the tumor mass and are one of the main producers of CC-chemokine ligand 18 (CCL18), which is believed to carry out important functions in the immunological interactions that promote tumor progression. Materials and Methods: Cytokines/chemokines were measured in bronchoalveolar lavage (BAL) from the tumor site and serum before and after resection in patients with proven non-small cell lung cancer (NSCLC). Results: CCL18 concentrations in BAL positively correlated with the radiologically determined tumor volume $(r=0.72, p=0.0003)$ in NSCLC. In addition, tumors with lymph-node metastasis exhibited significantly higher CCL18 concentrations in BAL ( $p=0.049$ ) than those without. Serum CCL18 concentrations did not differ significantly before and after tumor resection. Conclusion: The increased release of CCL18 with greater tumor size is most likely due to the accompanied growth of leukocyte infiltrate. With previous findings taken into account, this could be one factor contributing to tumor invasiveness and particularly lymphatic spread in patients with larger tumors.
\end{abstract}

Lung cancer is the leading cause of cancer-related death and is usually diagnosed at an advanced stage, where lymph node/distant metastases are present. Only in about one-third of patients with non-small cell lung cancer (NSCLC) the disease

This article is freely accessible online.

Correspondence to: Dr. Severin Schmid, Department of Thoracic Surgery University Hospital Freiburg, Hugstetter Straße 55, 79106 Freiburg, Germany. Tel: +49 076127090700, Fax: +49 076127090701, e-mail: severin.schmid@uniklinik-freiburg.de

Key Words: CCL18, tumor microenvironment, tumor associated macrophages, TAM, lymphatic spread. is diagnosed as localized, for which a complete resection is the treatment of choice and a cure is possible. Hence, in most cases systemic therapy is required, either as part of a multimodal treatment or as sole therapeutic option. Despite advances in individualized approaches and modern chemotherapeutic regimens, the course of the disease remains unfavorable (1-3).

It is widely acknowledged that the tumor microenvironment plays a critical role in tumor growth and spread, and in recent years, multiple therapeutic approaches have been developed based on this knowledge (4). In contrast to agents focusing on molecular targets such as the epidermal growth factor receptor (EGFR), and anaplastic lymphoma kinase (ALK), whose activity is confined to tumors with specific genetic alterations, immunotherapy is effective in various histological subtypes (5-8).

Tumor microenvironment consists of tumor cells, the leukocyte infiltrate and the tumor associated immunologic microenvironment. One of the key players, the tumor associated macrophages (TAMs) can make up a large fraction of the tumor mass (9). Depending on the tumor microenvironment, macrophages can be polarized into different functional states, of which the two extremes are known as the M1 and M2 phenotypes. M1 macrophages have been shown to carry out pro-inflammatory, cytotoxic and thus mostly anti-neoplastic effects, whilst the M2 phenotype is responsible for tissue remodeling and repair and is believed to be involved in the subversion of adaptive immunity and thus the immunological interactions that promote tumor growth and progression. TAMs in the tumor microenvironment are mostly found to have the M2 phenotype (10). TAMs secrete a specific pattern of cytokines and chemokines and are one of the main producers of CC-chemokine ligand 18 (CCL18) in this context $(11,12)$. CCL18 is responsible for the recruitment of naive T-cells and dendritic cells, and is capable of inducing regulatory T-cells. In the tumor microenvironment, it has been demonstrated to promote tumor spread and is believed to be one of the factors involved in the immune escape of tumor cells (13-17). 
To enable further insight into the interactions of TAMs and the tumor microenvironment, we conducted a study concerning CCL18 and associated cytokines involved in these immunological interactions and their correlation with clinical tumor biology in NSCLC.

\section{Materials and Methods}

In this prospective observational study, we enrolled 37 patients with proven NSCLC. The study was approved by our local Ethics Committee and registered as a clinical trial in the German Registry for Clinical Trials (DRKS-ID: DRKS00005415). All patients signed an informed consent form before participating in the study.

Inclusion criteria were the presence of a pulmonary nodule suspicious of primary lung cancer with no previous treatment in patients from whom bronchoalveolar lavage (BAL) samples were taken. Exclusion criteria were clinical or radiological signs of pneumonia, centrally located tumors, presence of other malignancies, previous radiation or chemotherapy, treatment with systemic or inhalative steroids and poor quality of the BAL sample (presence of ciliated epithelium, bloody samples and low recovery). In patients from whom serum samples were acquired, inclusion criterion was histologically proven NSCLC eligible for resection. BAL was performed $(n=25)$ using flexible bronchoscopes as described elsewhere (18).

The cytokines and chemokines CCL18, indoleamine 2,3dioxygenase (IDO), tumor necrosis factor (TNF), transforming growth factor $\beta$ (TGF $\beta$ ), and interleukin (IL)-1 $\beta$, IL4, IL6, IL8, IL10, and IL12 were analyzed via ELISA according to the manufacturer's recommendations (R\&D Systems, Minneapolis, MN, USA).

Serum samples were acquired from another cohort of patients with proven NSCLC which were eligible for tumor resection $(n=12)$ preoperatively, first day after operation and on day 10 after operation. CCL18 concentrations were also analyzed using ELISA.

Radiological tumor volume was determined by board-certified radiologists (ID, LJK) according to the recommendations by the Fleischner Society (19).

Data were recorded in a database designed in Microsoft Office Excel (Microsoft, Redmond, WA, USA) and GraphPad Prism 6.03 (GraphPad Software Inc., La Jolla, CA, USA) was used for statistical analysis. The D'Agostino-Pearson omnibus normality test was performed. Normally distributed datasets were compared using Student's $t$-test. For non-normally distributed data, Mann-Whitney test was employed. Correlation was calculated using Spearman's r. Results were considered significant if the $p$-value was less than 0.05 .

\section{Results}

Patients' characteristics. In total, 37 patients were included in the study. In all patients, histologically proven NSCLC was present, 24 classified as adenocarcinomas, 11 as squamous cell carcinomas and two as large-cell carcinomas.

CCL18 concentrations in BAL, but not in serum, correlate with radiologically determined tumor size. TAMs make up a large fraction of the leukocyte infiltrate and thus also of the tumor mass in solid tumors. To analyze possible increased immunological effects of this infiltrate with increased tumor size, we radiologically determined the mean tumor volume and correlated it with concentrations in BAL of CCL18 and associated cytokines that influence the immune reaction in patients with malignant tumors.

We showed that CCL18 concentrations in BAL positively correlate with the radiologically determined tumor volume $(\mathrm{r}=0.72, p=0.0003)$ in NSCLC (Figure 1a). Comparison of the radiologically determined tumor size with pathological tumor size in tumors that were resected confirmed correct radiological measurements $(\mathrm{r}=0.84, p<0.0001)$.

High CCL18 concentration in BAL is associated with lymph node metastasis. CCL18 concentrations are known to be elevated in patients with lung cancer and this is believed to influence immunological interactions in the tumor microenvironment involving tumor progression and metastasis. Detailed analysis of CCL18 expression and clinicopathological features was performed. We found significantly higher CCL18 concentrations in patients with lymph node-positive $(2,585 \pm 1,961 \mathrm{pg} / \mathrm{ml})$ than in those with nodal-negative disease (988 $\pm 860 \mathrm{pg} / \mathrm{ml} ; p=0.049$ ) (Figure 1b). No systematic associations concerning other clinicopathological features, such as distant metastasis or clinical tumor stage, were observed.

Interestingly, we found no link between tumor volume $(\mathrm{r}=0.15, p=0.64)$ and serum CCL18 concentrations (Figure 2a). In addition, there was no difference in CCL18 concentrations in serum immediately and medium-term after tumor resection (Figure $2 b$ ).

None of the other measured cytokines showed any association with clinical findings. TGF $\beta$, IL8, IL12 did not significantly differ in the different groups regarding clinical or pathological tumor stage. IL1 $\beta$, IL10 IFN $\gamma$ and TNF were also determined but their concentrations in most samples were below the detection limit of the ELISA used.

\section{Discussion}

TAMs are the most abundant immunological cells in the tumor microenvironment and have been associated with tumor progression in various solid tumors $(15,20,21)$. They are also the main producers of CCL18, which has been shown to have important functions in immunological interactions in the tumor microenvironment and thus influence tumor growth and spread $(14,15)$. Previous studies on lung cancer demonstrated that the accumulation of CCL18-positive TAMs in pathological sections was associated with a poor prognostic outcome (22). Correspondingly, high serum concentrations of CCL18 in lung adenocarcinoma were also associated with an unfavorable prognosis (23).

In this study, we showed for the first time that CCL18 concentrations in BAL from the lung portion affected by tumor increases with tumor size. Based on the knowledge we have from previous studies, this finding most likely 

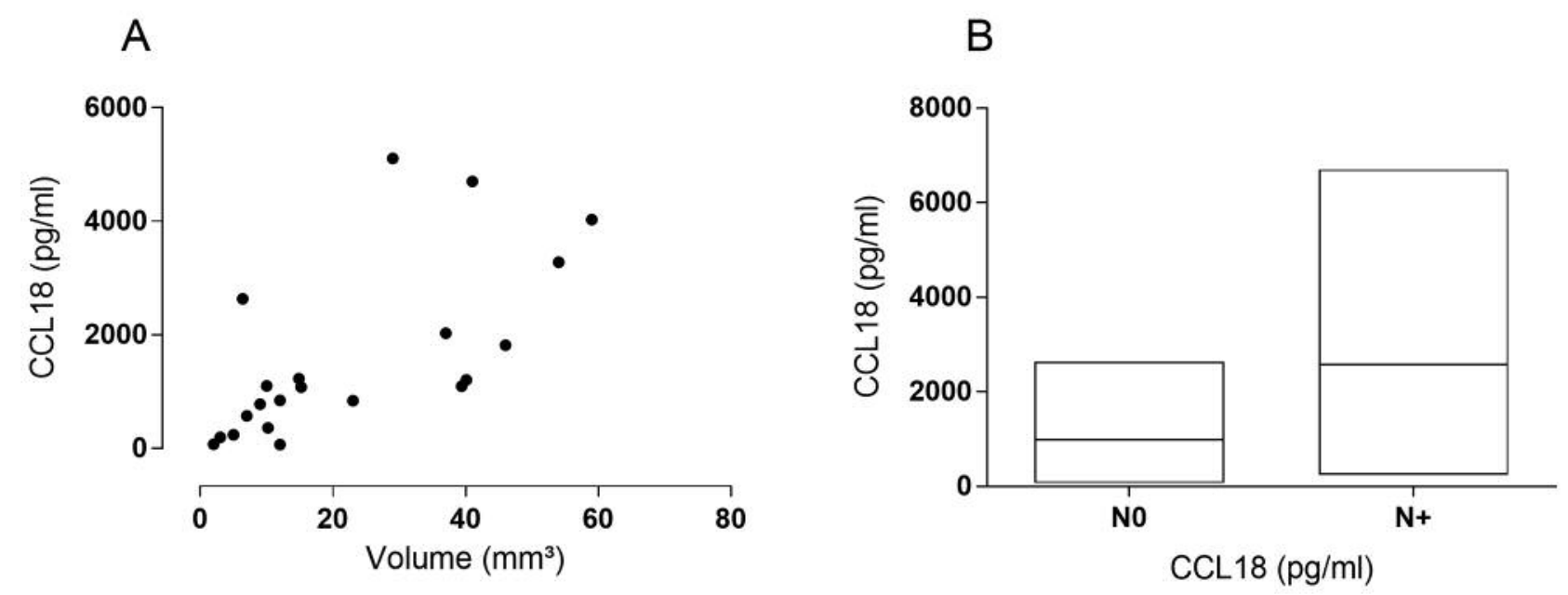

Figure 1. Correlation of tumor size and CC-chemokine ligand 18 (CCL18) concentration a in bronchoalveolar lavage (BAL) (A) and comparison of tumors with $(\mathrm{N}+)$ and without $(\mathrm{NO})$ presence of lymph-node metastasis $(B) . C C L 18$ concentrations in BAL from the tumor site positively correlated with the radiologically determined tumor volume $(r=0.72, p=0.0003)$. In tumors with lymph-node metastasis, CCL18 concentrations in BAL were significantly higher than in tumors without lymphatic spread $(p=0.049)$.
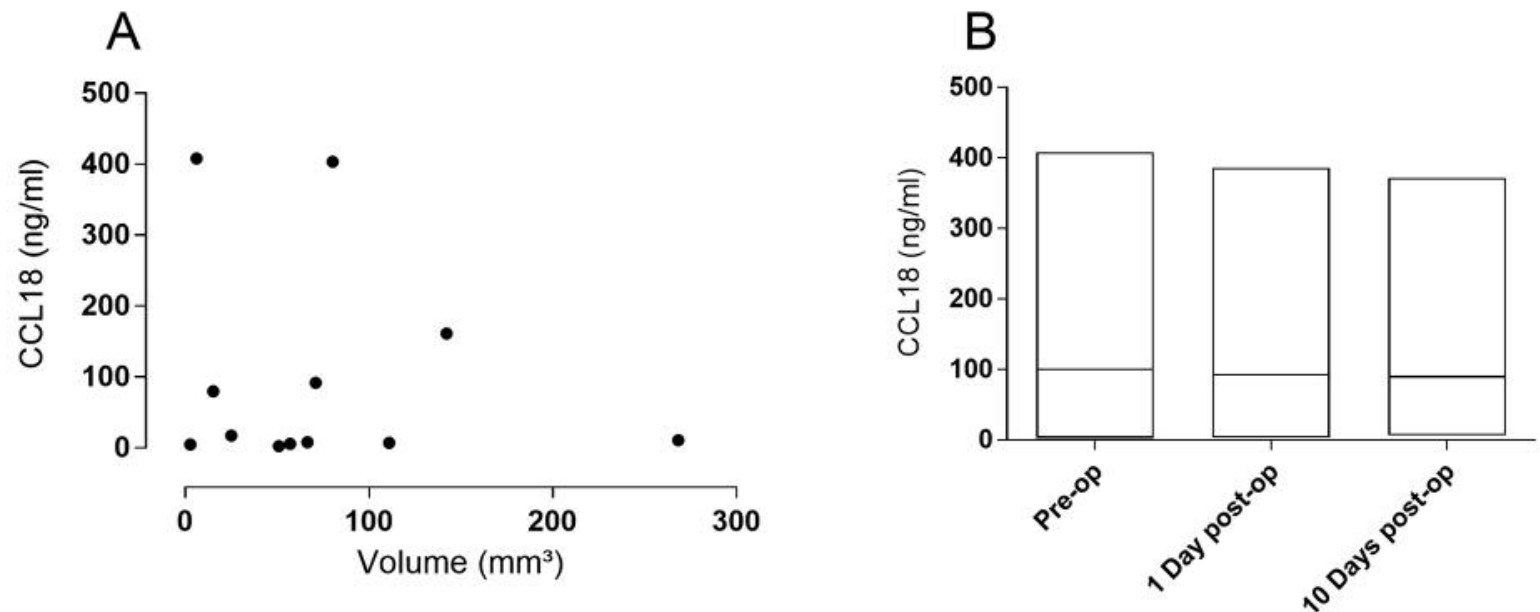

Figure 2. Correlation of tumor size and CC-chemokine ligand 18 (CCL18) concentrations in serum (A) and comparison before and after resection of the tumor (B). Serum CCL18 concentrations did not correlate with tumor volume $(r=0.15, p=0.64)$ and there were no differences before, immediately after and 10 days after tumor resection.

represents the growth of the leukocyte infiltrate represented by TAMs, which often make up a large fraction of the tumor, and their excessive CCL18 secretion $(9,10)$. CCL18 is known to carry out different immunomodulatory functions, including chemotaxis, and to participate in the homing of naive T-helper 4 cells and dendritic cells $(24,25)$. It has also been shown that it differentiates dendritic cells able to prime regulatory T-cells and thus induce tolerance (26). This action was suggested to lead to a failure of the immune system to adequately react to malignancies and kill tumor cells.
In the tumor microenvironment, CCL18 promotes epithelial to mesenchymal transition in different types of solid tumors, including NSCLC (13-15). In a recently conducted study by Shi and colleagues, it was shown that CCL18 modulates NSCLC cell invasion and migration via the nitrite reductase 1-engulfment and cell motility 1/dedicator of cytokinesis 180 (NIR1-ELMO1/DOC180) pathway and thus promotes tumor metastasis (22).

In NSCLC, tumor size is a prognosticator for the presence of lymph-node metastasis even in those with early disease 
stage and smaller tumors (27). Interestingly, we recorded significantly higher CCL18 concentrations in BAL from those with primary lung cancer with lymph node metastasis compared to those with tumors without affected locoregional lymph nodes at the time of sampling. These findings are in line with multiple previous studies, where high CCL18 expression in pathological sections was associated with lymph-node metastasis and peritumoral lymphangiogenesis in different tumor types, including $\operatorname{NSCLC~}(14,22,28)$. Moreover, in patients suffering from breast cancer, higher CCL18 levels in blood as well as in cancer stroma was associated with an increased occurrence of metastasis and tumor invasion, and reduced patient survival (29).

In conclusion, our data demonstrate an increased release of CCL18 with greater tumor size, which, considering previous data, is most likely due to the accompanied growth of the leukocyte infiltrate of which a large fraction is made up of TAMs. This could be one mechanism contributing to the clinical observation of a higher likelihood of lymphatic spread in patients with larger tumors.

\section{Conflicts of Interest}

There is no conflict of interest regarding the material discussed in this article.

\section{References}

1 Morgensztern D, Ng SH, Gao F and Govindan R: Trends in stage distribution for patients with non-small cell lung cancer: a National Cancer Database survey. J Thorac Oncol 5: 29-33, 2010.

2 Govindan R, Page N, Morgensztern D, Read W, Tierney R, Vlahiotis A, Spitznagel EL and Piccirillo J: Changing epidemiology of small-cell lung cancer in the United States over the last 30 years: analysis of the surveillance, epidemiologic, and end results database. J Clin Oncol 24: 4539-4544, 2006.

3 Howlader N, Noone AM, Krapcho M, Garshell J, Miller D, Altekruse SF, Kosary CL, Yu M, Ruhl J, Tatalovich Z, Mariotto A, Lewis DR, Chen HS, Feuer EJ CK: SEER Cancer Statistics Review, 1975-2011. Natl Cancer Inst, 2013.

4 Lorusso G and Rüegg C: The tumor microenvironment and its contribution to tumor evolution toward metastasis. Histochem Cell Biol 130: 1091-1103, 2008.

5 Lynch TJ, Bell DW, Sordella R, Gurubhagavatula S, Okimoto RA, Brannigan BW, Harris PL, Haserlat SM, Supko JG, Haluska FG, Louis DN, Christiani DC, Settleman J and Haber DA: Activating mutations in the epidermal growth factor receptor underlying responsiveness of non-small-cell lung cancer to gefitinib. N Engl J Med 350: 2129-2139, 2004.

6 Paez JG, Jänne PA, Lee JC, Tracy S, Greulich H, Gabriel S, Herman P, Kaye FJ, Lindeman N, Boggon TJ, Naoki K, Sasaki H, Fujii Y, Eck MJ, Sellers WR, Johnson BE and Meyerson M: EGFR mutations in lung cancer: correlation with clinical response to gefitinib therapy. Science 304: 1497-1500, 2004.

7 Soda M, Choi YL, Enomoto M, Takada S, Yamashita Y, Ishikawa S, Fujiwara S, Watanabe H, Kurashina K, Hatanaka H,
Bando M, Ohno S, Ishikawa Y, Aburatani H, Niki T, Sohara Y, Sugiyama $\mathrm{Y}$ and Mano H: Identification of the transforming EML4-ALK fusion gene in non-small-cell lung cancer. Nature 448: 561-566, 2007.

8 Ohaegbulam KC, Assal A, Lazar-Molnar E, Yao Y and Zang X: Human cancer immunotherapy with antibodies to the PD-1 and PD-L1 pathway. Trends Mol Med 21(1): 24-33, 2015.

9 Sica A, Schioppa T, Mantovani A and Allavena P: Tumourassociated macrophages are a distinct M2 polarised population promoting tumour progression: potential targets of anti-cancer therapy. Eur J Cancer 42: 717-727, 2006.

10 Mantovani A, Allavena P and Sica A: Tumour-associated macrophages as a prototypic type II polarised phagocyte population: role in tumour progression. Eur J Cancer 40: 16601667, 2004.

11 Mantovani A, Sozzani S, Locati M, Allavena P and Sica A: Macrophage polarization: tumor-associated macrophages as a paradigm for polarized M2 mononuclear phagocytes. Trends Immunol 23: 549-555, 2002.

12 Mantovani A, Sica A, Sozzani S, Allavena P, Vecchi A and Locati M: The chemokine system in diverse forms of macrophage activation and polarization. Trends Immunol 25: 677-686, 2004.

13 Ploenes T, Scholtes B, Krohn A, Burger M, Passlick B, MüllerQuernheim J and Zissel G: CC-chemokine ligand 18 induces epithelial to mesenchymal transition in lung cancer A549 cells and elevates the invasive potential. PLoS One 8: e53068, 2013.

14 Meng F, Li W, Li C, Gao Z, Guo K and Song S: CCL18 promotes epithelial-mesenchymal transition, invasion and migration of pancreatic cancer cells in pancreatic ductal adenocarcinoma. Int J Oncol 46(3): 1109-1120, 2015.

15 Chen J, Yao Y, Gong C, Yu F, Su S, Chen J, Liu B, Deng H, Wang F, Lin L, Yao H, Su F, Anderson KS, Liu Q, Ewen ME, Yao X and Song E: CCL18 from tumor-associated macrophages promotes breast cancer metastasis via PITPNM3. Cancer Cell 19: 541-555, 2011.

16 Azzaoui I, Yahia SA, Chang Y, Vorng H, Morales O, Fan Y, Delhem N, Ple C, Tonnel A-B, Wallaert B and Tsicopoulos A: CCL18 differentiates dendritic cells in tolerogenic cells able to prime regulatory T-cells in healthy subjects. Blood 118: 35493558, 2011.

17 Schutyser E, Richmond A and Damme J Van: Involvement of CC chemokine ligand 18 ( CCL18) in normal and pathological processes. J Leukoc Biol 78(1): 14-26, 2005.

18 Schmid S, Kübler M, Korcan Ayata C, Lazar Z, Haager B, Hoßfeld M, Meyer A, Cicko S, Elze M, Wiesemann S, Zissel G, Passlick B and Idzko M: Altered purinergic signaling in the tumor associated immunologic microenvironment in metastasized non-small-cell lung cancer. Lung Cancer 90(3): 516-521, 2015.

19 Naidich DP, Bankier AA, MacMahon H, Schaefer-Prokop CM, Pistolesi M, Goo JM, Macchiarini P, Crapo JD, Herold CJ, Austin JH and Travis WD: Recommendations for the management of subsolid pulmonary nodules detected at CT: a statement from the Fleischner Society. Radiology 266: 304-317, 2013.

20 Hamada I, Kato M, Yamasaki T, Iwabuchi K, Watanabe T, Yamada T, Itoyama S, Ito $\mathrm{H}$ and Okada K: Clinical effects of tumor-associated macrophages and dendritic cells on renal cell carcinoma. Anticancer Res 22: 4281-4284, 2002. 
21 Lee C-H, Espinosa I, Vrijaldenhoven S, Subramanian S, Montgomery KD, Zhu S, Marinelli RJ, Peterse JL, Poulin N, Nielsen TO, West RB, Gilks CB and van de Rijn M: Prognostic significance of macrophage infiltration in leiomyosarcomas. Clin Cancer Res 14: 1423-1430, 2008.

22 Shi L, Zhang B, Sun X, Zhang X, Lv S, Li H, Wang X, Zhao C, Zhang H, Xie X, Wang Y and Zhang P: CC chemokine ligand 18(CCL18) promotes migration and invasion of lung cancer cells by binding to Nir1 through Nir1-ELMO1/DOC180 signaling pathway. Mol Carcinog doi: 10.1002/mc.22450, 2016.

23 Plönes T, Krohn A, Burger M, Veelken H, Passlick B, MüllerQuernheim J and Zissel G: Serum level of CC-chemokine ligand 18 is increased in patients with non-small-cell lung cancer and correlates with survival time in adenocarcinomas. PLoS One 7: e41746, 2012.

24 Jonuleit H, Schmitt E, Schuler G, Knop J and Enk AH: Induction of interleukin 10-producing, nonproliferating CD4(+) T-cells with regulatory properties by repetitive stimulation with allogeneic immature human dendritic cells. J Exp Med 192: 1213-1222, 2000

25 Roncarolo MG, Levings MK and Traversari C: Differentiation of $\mathrm{T}$ regulatory cells by immature dendritic cells. J Exp Med 193: F5-9, 2001.
26 Chang Y, de Nadai P, Azzaoui I, Morales O, Delhem N, Vorng H, Tomavo S, Ait Yahia S, Zhang G, Wallaert B, Chenivesse C and Tsicopoulos A: The chemokine CCL18 generates adaptive regulatory $\mathrm{T}$ cells from memory $\mathrm{CD} 4+\mathrm{T}$ cells of healthy but not allergic subjects. FASEB J 24: 5063-5072, 2010.

27 Bao F, Yuan P, Yuan X, Lv X, Wang Z and Hu J: Predictive risk factors for lymph node metastasis in patients with small size non-small cell lung cancer. J Thorac Dis 6: 1697-1703, 2014.

28 Zhang BC, Gao J, Wang J, Rao ZG, Wang BC and Gao JF: Tumor-associated macrophages infiltration is associated with peritumoral lymphangiogenesis and poor prognosis in lung adenocarcinoma. Med Oncol 28: 1447-1452, 2011.

29 Yuan R, Chen Y, He X, Wu X, Ke J, Zou Y, Cai Z, Zeng Y, Wang L, Wang J, Fan X, Wu X and Lan P: CCL18 as an independent favorable prognostic biomarker in patients with colorectal cancer. J Surg Res 183: 163-169, 2013.

Received June 18, 2016

Revised July 11, 2016

Accepted July 15, 2016 